\title{
Reflections on the role of a workplace mediator
}

\section{Tony Bennett}

\begin{abstract}
This article is a reflection on my time as an internal mediator and, I hope also, a guide for readers who are considering introducing or taking up the role. To that end, the discussion covers my early expectations, the first time in the role, different approaches to the role I have encountered both as a practicing mediator and also as a researcher and closes with some reflection on the future. This article is an adaptation of an original paper for the UK Professional Mediation Association conference 2014. To that end, I have sought to develop some of the themes based more specifically on my and colleagues' research on mediation across a number of sectors in the UK, in particular within higher education.
\end{abstract}

\section{Keywords}

Mediation, workplace mediator, internal mediation

\section{Introduction}

I'm not sure what first prompted me to put myself forward for training as an internal mediator. As an academic in the HRM division of my business school at the time, I had a keen interest in workplace conflict and its resolution. It was probably a combination of this and also the discovery that the University had an established mediation service that led me to think: 'Why not!'

'T've been a manager, so I know how to manage conflict.' 'T've been a trade union local representative and TUC officer. So I know how to find solutions to workplace problems.' 'As an academic, there might be the opportunity to do some researchin the area.' Looking back on that decision a number of years on, I don't think then that I fully appreciated the challenges, most certainly the challenge to move from being a problem solver to a facilitator of solution seeking; but conversely, the professional and collegiate satisfaction that the role would alsobring.

The discussion that follows acknowledges the seminal contribution of research on the US Postal Service and the efficacy of its internal mediation initiative (Bingham and Pitts, 2002; Lipsky et al., 2003). Furthermore, the growing and influential general research on workplace conflict and its management (Teague and Roche, 2012; Lipsky et al. 2016; Saundry et al., 2016b) and, in particular, mediation (Roche and Teague, 2012; Latreille and Saundry, 2014; Kenny, 2014) remains a key backdrop for the discussion that follows. However, the focus of this paper whilst informed by this valuable knowledge is to consider in particular the role of the internal mediator and the broader understanding of conflict management we can draw from such an endeavour. 


\section{Reviewing the literature}

In terms of recent UK government strategy and policy on managing workplace conflict (Gibbons, 2007; BIS, 2011), it can be argued that mediation as an alternative dispute resolution option has grown in prominence. Current research and business practice supports this argument that, in these times of more individualised employment relations, mediation offers a degree of equality for the employee in addressing workplace conflict that is absent in other more 'formal' dispute resolution procedures (Latreille, 2011; ACAS/CIPD, 2013). Furthermore, there have been early efforts to conceptualise the process (See RidleyDuff and Bennett, 2011; Curran, 2015). Curran's (2015) study of the role of mediators in Ireland usefully highlights the type of contrasting 'behaviours' reported in 'managing' the process. Significantly, her findings suggest that sometimes a more 'directive' rather than 'facilitative' approach is utilised; where in 'directive mediation the mediator makes non-binding recommendations that parties may or may not accept' in contrast to 'a facilitative mediation [where] the mediator focuses on encouraging the parties to find their own solution to the issues' (Ridley-Duff and Bennett, 2011:110). My reflections here are based more on facilitativeapproaches.

In this context, an element of workplace mediation less well considered, certainly in the UK, is the specific role and efficacy of the internal mediator within that process. At this stage in our discussion, it is useful to consider some key definitions; For ACAS:

Mediation ... Is where an impartial third party, the mediator, helps two or more people in dispute to attempt to reach an agreement. Any agreement comes from those in dispute, not from the mediator. The mediator is not there to judge, to say one person is right and the other wrong, or to tell those involved in the mediation what they should do. The mediator is in charge of the process of seeking to resolve the problem but not the outcome (2010:3).

Internal mediators may be employees who act as internal mediators in addition to their day jobs .... They can work individually or in pairs as co- mediators (ibid.).

For mediation to be effective, mediators need to be trained in the techniques of mediation and hold a qualification such as the ACAS Certificate in Internal Workplace Mediation (CIWM). They also need to understand their role and how it fits within the organisation's dispute resolution procedures, and other policies and procedures such as bullying and harassment and diversity policies (2013:10).

An exception to the typically more indirect references to the internal mediator in the current literature is Broughton et al.'s (2014) evaluative study of the overall effectiveness of the CIWM. They interviewed 150 mediators who had attended ACAS training over a 12-month period. Key findings were that:

- High levels of success rates were reported across organisations.

- Nearly $50 \%$ of respondents, however, did little mediation in the year following training.

- A high number of HR practitioners in the sample suggests ACAS needs to market its training to a wider range of participants.

- Supportive organisational culture and senior management were significant drivers for successful mediation services. 
Saundry et al.'s (2016a) research on the efficacy of mediation is another of the few studies on the broader role and impact of the workplace mediator, specifically from the disputant's perspective. Its central conclusions were that overall disputants valued the role of the mediator (internal and external). However, in most cases that intervention had come too late in the dispute, also parties had often not fully 'bought into' mediation. Therefore, many settlements were short lived and at best, mediation provided an opportunity for people to 'have their say' but not really resolving the underlying issues that caused the dispute. This short review raises the crucial question 'why would an organisation set up an internal mediationservice?

\section{The strengths and limitations of internal mediation}

In Saundry et al.'s (2013) study on the disputants' views, there was evidence that the use of internal mediation has advantages, in that external mediators are tasked to come in and resolve a dispute in a limited timeframe. By contrast, the internal mediators often spend more time on the process and also provide more easily the possibility of follow up in the process. Crucially, in terms of managing the process the research suggested that the internal mediator offered the advantage of being able to manage the practical elements of rooms, initial meeting timings etc. which an outside mediator often has not the resources to address.

Conversely, there are disadvantages to an organisation employing a team of internal mediators. The balance between the number of disputes appropriate for mediation and whether it is more cost effective to bring in an external expert is central. This is certainly true when committing resources to the training and subsequent maintenance of an internal mediation team. Equally key is that, due to work commitments, turnover of staff and actual opportunities to practice mediation, not all that team build up the expertise of the external mediator (See Broughton et al., 2014). Often, therefore, the service is dependent on a core number of individuals. Unsurprisingly, given these resourcing issues, research has shown that small companies are less likely to use in-house mediation (Fox, 2005; Latreille, 2011) in contrast to large organisations (Saundry et al., 2013; Saundry and Wibberely, 2014: 31-33).

Nonetheless, if dealing with high numbers of disputes, there remain clear advantages over 'calling in' an external mediator to an organisation. Firstly, it is often both cheaper and faster than using conventional disciplinary and grievance procedures for appropriate cases (Gennard et al.,2016: 330-332). Specifically, in terms of the focus of this paper, internal mediators are often in a much better position to understand the organisational context which may help participants to find a sustainable resolution. Furthermore, if the organisation has a trained team of mediators they can also facilitate key conflict handling skills development amongst line managers; they may even, it is argued, contribute to a change in the culture of conflict management (Bennett, 2014; Saundry and Wibberley, 2015).

Nevertheless, from a HR strategic perspective, the support of senior management is vital if internal mediation is going to be sustainable. As Gennard et al. (2016) argue, it is also crucial that the scheme has a champion who occupies an influential position within the organisation. Crucially, as Gennard et al. further maintain, although it may be tempting to simply select HR practitioners as mediators, evidence suggests that 'when mediators are drawn from different parts of the organisation, it is more likely that support for, and awareness of, the service will increase and that an emphasis on early resolution will be encouraged' (ibid:333). This is particularly so, it can be argued, if prominent individuals such as union reps or senior managers take up 
those roles (Latreille and Saundry, 2016). To summarise, from my practical experience as a mediator and also the research I have undertaken, I would argue that in order to introduce and maintain an effective internal mediation service, it is necessary to:

- Review your existing disciplinary, grievance and dignity at work procedures and see whether mediation can be built into the early stages, placing a greater emphasis generally on the importance of conflictresolution.

- Use your mediators flexibly - think about different ways in which trained mediators can be used in addition to conventional mediations. For example, they could be used to train managers, assist in facilitated meetings and also to coach managers in teams where there is a particular problem.

- Make sure that resources are in place to evaluate mediations but also to follow this up at a later point to see whether the solution has been sustained. Evaluations will also help to establish the value of the service (See Gennard et al., 2016).

\section{Initial expectations, the process and confronting the realities of internal mediation}

You have completed your practical training with your provider. You produce the portfolio of evidence of learning to achieve your accreditation, finally aware that you hadn't quite realised how long that would take! You then await your first assignment from your coordinator. It is valuable at this stage to briefly outline, with respect to the organisations of which I have experience, the process of assigning a mediator to the disputants. The mediation co-coordinator is the first point of referral through the channels established in that particular organisation. This could be HR, training and development, the equality team, the union, line managers or directly from the disputants. They will 'triage' the case and decide if mediation would be of value to the disputants. As an internal mediator you are typically on a team from which the coordinator will make their choice.

The basis for that choice varies across the organisation but is typically based, of course, on availability or having no direct knowledge of the disputants (in a university this would mean, for instance, allocating a mediator from another school or faculty). Biographical variables, such as ones' position or gender, in my experiences can occasionally be a factor for the disputants; in which case the mediator may seek to accommodate this request. On occasion, again in my experience, for disputes amongst more senior colleagues at a university, networks of institutions if in existence can enable a 'neutral' mediator to be brought in from another university to facilitate the process, or alternatively they engage the services of an external provider.

\section{The first time}

Your first thoughts: They said nothing on the course about having to email the disputants? How do I word it? In fact, why are they so hard to contact? How do I plan to get them from position to interest based? Why did I volunteer to do this? In truth the first mediation (and probably the second and third) is very daunting in my experience. Nevertheless, for many organisations this is alleviated by dual mediation, and having later also done this with a new mediator in our team it can prove a lot less stressful. In reality, as 
with all training I feel that the role plays, the portfolio building and extra reading can only take you so far. Ultimately, for this and indeed every case you undertake, it is crucial to have faith in your own ability. To draw on your organisational knowledge and good planning but, fundamentally, also the empathetic and listening skills that first made you realise that you could do the job, and with practice do it rather well.

I completed my first assignment reasonably effectively. The feedback from the disputants was generally positive, although as I note below, there are always limits to what that can be achieved. Nevertheless, to help colleagues continue to work together, to rebuild their relationship, to better understand how the other thinks and, therefore, why they act the way they do within that relationship, remains for me a successful outcome and why I believe that mediation is a valuable tool in addressing workplace conflict. To this end, and in part concert with Curran's (2015) findings on mediator style and behaviour, I believe it is hard for any mediator not to, in some situations, briefly adopt a more 'directive' stance in order to keep the process on track towards a resolution. I do, however, believe that genuine facilitation must remain the norm.

This said, occasionally I felt the outcome, even when the disputants shook hands and ostensibly agreed to the solutions identified, for many reasons was only partially successful in its implementation. Crucially, in certain cases, the first key barrier to success remains, for whatever reasons, one or both parties not really having fully 'bought into' the process. The second is that, in reality, all workplace mediation takes place within the context and therefore the constraints of the influence, management style and strategy of those who manage the disputants from higher in the organisation.

\section{Putting internal mediation in context: 'Managing academics is like herding cats'}

For a number of management writers, managing workers in the workplace can best be described as 'a bit like herding cats' (Bennis, 1999; Watson, 2006). Therefore, you will perhaps recognise my satisfaction, whilst researching mediation in higher education (HE), that two HR managers both reported that 'managing academics is like herding cats' (See Bennett, 2013). The metaphor was clearly an expression for them of the challenges facing HR professionals in supporting the management of employees who by the nature of their work are strongly protective of their autonomy. In defence of the academic, it could be argued that this propensity to object to being closely managed is what makes them good at what they do. This early insight into the nature of the culture of $\mathrm{HE}$, and specifically the academics as a sub-group, was to hold me in good stead when I began mediating disputes between academic staff. The resulting conflict when managers in the sector, under pressure to achieve ever more demanding targets, seek to increasingly micro-manage these traditionally very independent workers is easier to understand. I am sure for many readers working in other sectors the 'herding cats' analogy reads equally well when trying to manage conflict amongst multiple professional groups - be they doctors, salespeople, $R \& D$ colleagues or senior managers. As an internal mediator, the lesso for me was to really know the culture and, crucially, the sub-cultures, of your organisation in order to be able to effectively facilitate disputes amongst staff for whom challenges to their position of autonomy does not always come easy. 


\section{Some closing thoughts}

I enjoyed my time as an internal mediator. I remain convinced that with the good will of the disputants to 'give it a try' that many workplace disputes lend themselves well to the process. What is equally clear for me is that mediation also develops a body of skills and knowledge that we should be seeking to develop in all of our managers. As I alluded to above, often the limitation facing any mediator is that unless the dispute is specifically between manager and team member, or team colleagues, there is another typically higher level of authority in that workplace whose management style or strategy can play a major influence on the degree to which any dispute can be fully resolved. At best, maybe the mediator's goal is to achieve a resolution between disputants within the context of their environment. A major advance would be, therefore, to steer that whole workplace environment towards a more conciliatory approach to managing the employment relationship. It is here perhaps that the unique mind-set offered by mediation could play a greater role in managing the causes and consequences of workplace disputes in organisations.

In closing, mediation is not a panacea. Some disputes are always better resolved through more traditional channels, such as grievance and performance management. However, my hope is that I have offered some insight to readers into the role of internal mediator and also to reiterate that it offers an excellent opportunity to develop new skills, knowledge and insight whilst genuinely providing colleagues with a less stressful and more empowering route to seeking an equitable outcome to their workplace disputes. 


\section{References}

ACAS/TUC (2010) Mediation: A Guide for Trade Union Representatives London, ACAS Publications

ACAS/CIPD (2013) Mediation: An Approach to Resolving Workplace Issues London, ACAS Publications

Bennett, T. (2013) “Workplace Mediation and the Empowerment of Disputants: Rhetoric or Reality?" Industrial Relations Journal, 44 (2)

Bennett, T. (2014) The Role of Workplace Mediation: A Critical Assessment Personnel Review, 43 (5)

Bennis, W. (1999) Managing People is like Herding Cats Executive Excellence Publishing.

Bingham, L. and D. Pitts (2002) "Highlights of Mediation at Work: Studies of the National REDRESS Evaluation Project" Negotiation Journal, 18: 149-160.

BIS (2011) Resolving Workplace Disputes: Government Response to the Consultation

London, Department for Business Innovation and Skills

Broughton, A., S. Ledermaier and A. Cox (2014) An Evaluation of the Impact of the Internal Workplace Mediation Training Service ACAS research paper 7/14 London, ACAS Publications

Curran, D. (2015) "Workplace Mediation in Ireland: Bridging the Research-Practice Gap", Journal of Mediation \& Applied Conflict Analysis, 2 (1)

Fox, M. (2005) Evaluation of the ACAS Pilot of Mediation, Appeals and Employment Law Visits Services to Small Firms ACAS Paper 05/05 London, ACAS Publications

Gennard, J., G. Judge, T. Bennett and R. Saundry (2016) Managing Employment Relations $6^{\text {th }}$ ed. London, CIPD Publications

Gibbons, M. (2007) Better Dispute Resolution: A Review of Employment Dispute Resolution in Great Britain London, Department of Trade and Industry

Kenny, T. (2014) "Developing the conversation about workplace mediation", Journal of Mediation \& Applied Conflict Analysis, 1 (1).

Latreille, P. (2011) Workplace Mediation: a Thematic Review of the ACAS/CIPD Evidence ACAS Research Paper, 13/11 London, ACAS Publications

Latreille, P. and R. Saundry (2014) "Mediation" in Roche, W., P. Teague, P. and A. Colvin (eds.) The Oxford Handbook on Conflict Management Oxford, Oxford University Press

Latreille, P. and R. Saundry (2016) "Transforming the Culture of Conflict Management: Lessons from Inhouse Mediation" in Saundry, R., P. Latreille and I. Ashman eds. Reframing resolution: Innovation and Change in the Management of Workplace Conflict London, Palgrave Macmillan

Lipsky, D., R. Seeber and R. Fincher (2003) Emerging Systems for Managing Workplace Conflict: Lessons from American Corporations for Managers and Dispute Resolution Professionals San Francisco, Jossey-Bass.

Lipsky, D., A. Avgar and J. Lamare (2016) “The Evolution of Conflict Management Policies in US Corporations: From Reactive to Strategic" in Saundry, R., P. Latreille and I. Ashman, eds. Reframing Resolution: Innovation and Change in the Management of Workplace Conflict London, Palgrave Macmillan

Ridley-Duff, R. and T. Bennett (2011) “Towards Mediation: Developing a Theoretical Framework to Understand Alternative Dispute Resolution” Industrial Relations Journal, 42 (2): 106-123

Roche, W. and P. Teague (2012) The Growing Importance of Workplace ADR 
International Journal of Human Resource Management, 23 (3): 447-458.

Saundry, R., T. Bennett and G. Wibberley (2013) Workplace mediation: The Participant Experience ACAS research paper 2/13 London, ACAS Publications

Saundry, R. and Wibberley (2014) Workplace Dispute Resolution and the Management of Individual Conflict - A

Thematic Analysis of Five Case Studies ACAS research paper 6/14 London, ACAS Publications

Saundry, R. and G. Wibberley (2015) Workplace Mediation -Transforming the Culture of Conflict Management? CIPD Applied Research Conference Dec. 2015

Saundry, R., T. Bennett and G. Wibberley (2016a) "Inside the Mediation room - Efficiency, Voice and Equity in Workplace Mediation" International Joumal of Human Resource Management. DOI:10.1080/09585192.2016.1180314

Saundry, R., D. Adam, I. Ashman, C. Forde, G. Wibberley and S. Wright (2016b) Managing individual Conflict in the Contemporary British Workplace ACAS paper: 02/16 London, ACAS Publications

Teague, P. and W. Roche (2012) "Line Managers and the Management of Workplace Conflict: Evidence from Ireland" Human Resource Management Journal, 22 (3): 235- 251

Watson, T. (2006) Organising and managing work, $2^{\text {nd }}$ Ed. London, FT, Prentice Hall

\section{Biography}

Tony Bennett is currently a visiting fellow at Sheffield Business School, Sheffield Hallam University. He is also an associate lecturer providing $\mathrm{PhD}$ supervision and teaching employee relations to undergraduate and postgraduate students. Following a career in the ICT industry, as an engineer and manager, he spent some time promoting workplace learning, including with the TUC, before moving into HE. At this time, he also acted for a number of years as an internal mediator. Tony's current research interests include: the management of conflict in the workplace; the role of trade unions in employee relations practice; the impact of domestic violence in the workplace; and the efficacy of a Freirean pedagogy in adult education. He is co- author of the CIPD core textbook Managing Employment Relations (Gennard, Judge, Bennett and Saundry, 2016). 